\title{
$\mathrm{PH} 99_{\text {actualidad }}$
}

\section{Una aproximación al paisaje cultural mediante etnografía virtual complementa el conocimiento experto de la percepción social}

El proyecto PAYSOC tiene como finalidad principal generar una metodología innovadora de análisis de los paisajes culturales andaluces mediante la aplicación de la etnografía virtual para incorporar el punto de vista de los agentes locales, de forma que se pueda sancionar, modificar y/o complementar la valoración experta, en línea con los principios de la construcción colaborativa del conocimiento, el paradigma participativo del patrimonio cultural y el uso de los contenidos proyectados en el mundo digital por parte de las personas interesadas. Este proyecto surge en el marco de la línea de investigación desarrollada por el Laboratorio del Paisaje Cultural del IAPH vinculada a la implementación del Convenio Europeo del Paisaje que tiene en la identificación de agentes y la incorporación de sus puntos de vista uno de sus principales objetivos.

Isabel Durán Salado, Silvia Fernández Cacho | Centro de Documentación y Estudios del IAPH

Url de la contribución <www.iaph.es/revistaph/index.php/revistaph/article/view/4593>

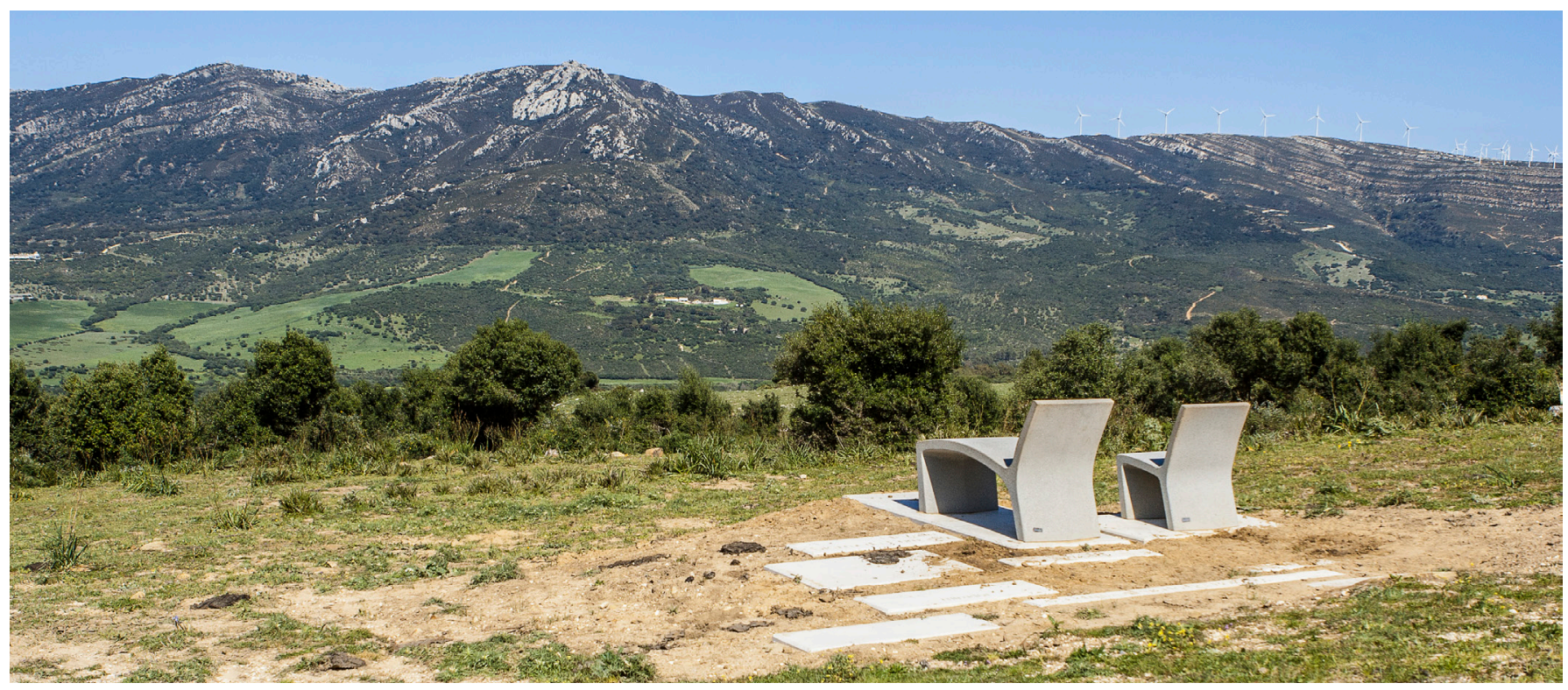

Mirador en el Paisaje de Interés Cultural de la ensenada de Bolonia (Tarifa, Cádiz) | Fondo Gráfico IAPH (Jesús Granada)

En el mes de agosto de 2019 fue aprobado por el Ministerio de Ciencia, Innovación y Universidades el proyecto Paisaje y Sociedad. Análisis de la Percepción Social en Paisajes Culturales (PAYSOC) (RTI2018096611-B-100) tras su presentación, dentro del programa "Retos de la Investigación", a la convocatoria realizada por la Agencia Estatal de Investigación en el año 2018.
Su objetivo principal es el desarrollo de una metodología de análisis de la percepción social en paisajes culturales mediante el uso de la etnografía virtual (HINE, 2004). Por ello, la propuesta pasa por explorar las potencialidades que ofrece la etnografía virtual como una primera vía para superar el posible sesgo producido por los estudios expertos que no contemplan la percepción de los diferentes agentes y grupos sociales involucrados en su 


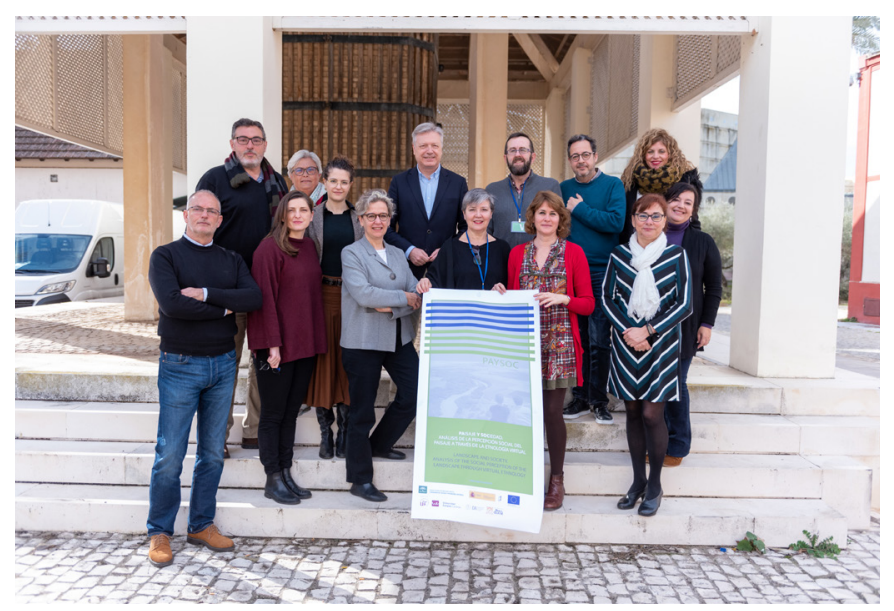

Componentes del equipo de investigación del proyecto PAYSOC en la sede del IAPH tras la primera reunión de trabajo | foto Fondo Gráfico IAPH (Eugenio Fernández Ruiz)

proceso de patrimonialización. En PAYSOC, el abordaje de la percepción social en los paisajes culturales se realizará desde un enfoque cualitativo, tratando de contrastar el conocimiento vernáculo con el experto. Para ello se partirá del análisis de un grupo de treinta paisajes significativos, seleccionados entre los incluidos en el Registro de Paisajes de Interés Cultural de Andalucía (R-PICA) ya identificados y caracterizados sin el concurso de la población local. La metodología resultante también se validará en los paisajes andaluces anteriormente seleccionados a los que se sumarán dos casos de estudios declarados patrimonio mundial fuera del marco andaluz, como son el paisaje cultural de Risco Caído y Montañas Sagradas de Gran Canaria (España) (ver en este mismo número pp. 17-19) y Ferrara, ciudad renacentista, y su delta del Po (Italia).

La mutidisciplinariedad es otra de las cuestiones a resaltar en el proyecto. Además de contar con una importante diversidad de perfiles profesionales (antropología, historia del arte, arqueología, arquitectura, historia, geografía, sociología, gestión cultural, turismo y marketing digital), el equipo reúne a cinco organismos de investigación, cuatro nacionales y uno internacional: Universidad de Sevilla, Universidad Pablo Olavide, Universidad Europea de Canarias y Universidad de Ferrara, coordinados por el Instituto Andaluz del Patrimonio Histórico.
El proyecto incluye un plan de difusión que, además de visibilizar el proyecto, persigue su difusión científica y técnica. Con ese fin se ha elaborado un plan de marketing que, pasando por la definición de su propuesta de valor y la identificación de los perfiles de usuarios diferenciados, ha desarrollado una identidad digital del proyecto a través de su sitio web www.iaph/paysoc.es. Dentro de las estrategias de visibilidad se contará con la comunicación institucional a través del sitio web IAPH y sus redes sociales, el diseño de una identidad corporativa del proyecto, un plan de marketing digital, la participación en eventos académicos y en revistas especializadas, y la promoción en medios universitarios.

Los resultados y aportaciones del proyecto tendrán su impacto tanto en el ámbito científico-técnico como en el social y económico. Dentro del científico-técnico, el proyecto realizará una aportación singular y metodológicamente novedosa, tanto por la aproximación mediante la etnografía virtual como por su carácter multidisciplinar que se hará patente a través de cuatro ámbitos de trabajo:

> Diseño y validación de una propuesta metodológica para el análisis de la percepción social a partir del uso de la etnografía virtual que permitirá complementar la visión experta actualmente predominante en el análisis de la percepción social en materia de paisajes culturales. Se logrará así la generación de un procedimiento metodológico susceptible de ser utilizado para otros estudios paisajísticos y patrimoniales.

$>$ Aportaciones metodológicas que permitirán avanzar en el proceso de implementación del Convenio Europeo del Paisaje en España (CEP), en lo relativo a la sensibilización, formación y educación, identificación y calificación y definición de objetivos de calidad paisajística (art.6) y la asistencia científica e intercambio de

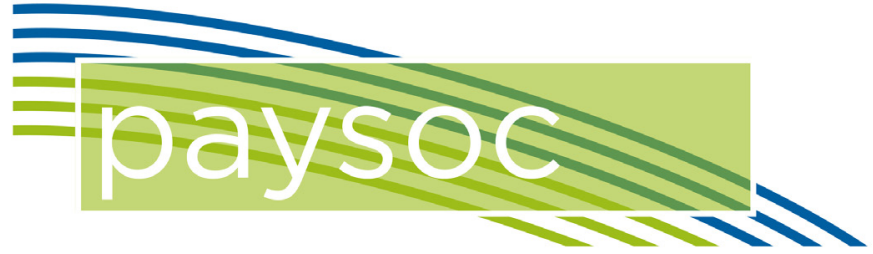




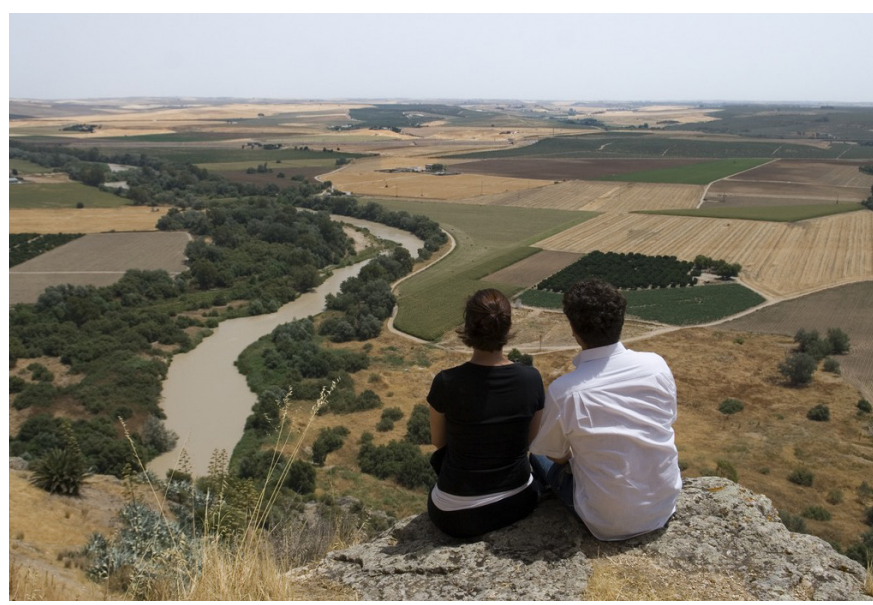

Paisaje de nterés cultural de Almodóvar del Río (Córdoba) | Fondo Gráfico IAPH (Juan Carlos Cazalla)

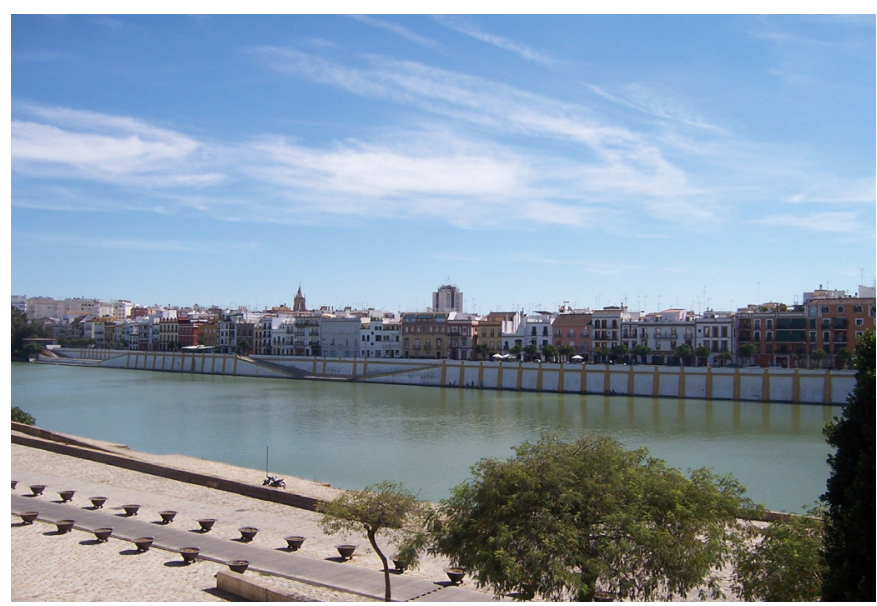

Paisaje histórico urbano de Sevilla | foto Fondo Gráfico IAPH

resultados de investigación en proyectos de investigación (art.8).

> Aproximación a una nueva dimensión analítica al Registro de paisajes de interés cultural de Andalucía u otros inventarios análogos, incorporando el conocimiento extraído del análisis de la percepción social en un conjunto significativo de paisajes culturales identificados y caracterizados.

$>$ Contribución al establecimiento de nuevos indicadores para valorar e incluir las visiones no expertas en los nuevos paisajes culturales para incorporar a la caracterización de los paisajes culturales.
Dentro del ámbito social y económico, sus logros y aportaciones se harán patentes en la aplicación de los resultados obtenidos para la elaboración de propuestas de objetivos de calidad paisajística, una herramienta clave a la hora de aplicar el CEP al involucrar el compromiso del conjunto de agentes sociales de un paisaje cultural interesados en su gestión sostenible. Por todo ello, en este ámbito, las propuestas del proyecto ayudarán a diseñar estrategias para hacer más viables las actividades productivas en paisajes culturales relacionados con la obtención y transformación de los recursos agrosilvopastoriles, agrarios, mineros y de la energía; corregir y prevenir el impacto del turismo en aquellos paisajes culturales más visitados; proponer fórmulas para proyectar una imagen más atenta a sus valores patrimoniales; y realizar acciones y aportar herramientas para la sensibilización, formación y educación en materia de paisajes culturales.

\section{BIBLIOGRAFÍA}

- HINE, C. (2004) Etnografía virtual. Barcelona: Editorial UOC, 2004 